\section{A CASE OF ACUTE PORPHYRIA}

BY

\section{Q. H. GIBSON, M.D., Ph.D.}

\section{C. HARRISON, D.Sc., Ph.D.}

\section{AND}

D. A. D. MONTGOMERY, M.D., M.R.C.P. (From the Department of Biochemistry, Queen's University, Belfast, and the Royal Victoria Hospital, Belfast)

Three years ago a patient with severe abdominal pain and nervous lesions was admitted to hospital. Laboratory investigation established a diagnosis of acute porphyria. A sample of porphyrin was obtained from the urine, but was not subjected to detailed examination at that time.

In view of recent interest in this rare condition-e.g., Hare and Wilmore, 1948 ; Petrie, 1948 ; Davies, 1949and particularly in view of the suggestion by Discombe (1948) that cases might be looked for in Northern Ireland, it seemed desirable to investigate this patient in more detail and record our findings.

\section{Case Report}

The patient, a girl aged 17, had had attacks of dull cramp-like para-umbilical pain for the previous four to five years. These attacks coincided with the beginning of the menstrual period and usually lasted from 12 to 24 hours. The attacks were stated to have shown a tendency to increase in severity as she got older. They were seldom accompanied by vomiting, but obstinate constipation was a constant feature. The periods were regular, occurring every 21 days and lasting for seven days. About 18 months previously there had been a mild attack of jaundice lasting for three weeks.

Two days before admission to hospital, on the fifth day of her menstrual period, the patient had a severe and protracted bout of abdominal pain and went to bed. Later that day, on getting up, she felt weak, and found that her limbs were shaking to such an extent that she could not control them. By the next day the tremor had passed off, but she still felt ill and the severe abdominal cramps recurred frequently. The spasms lasted for some minutes and recurred approximately every half-hour. The pain, dull and colicky in nature and situated in the umbilical region, left her exhausted and weak, and she vomited on several occasions. She had been constipated since the onset of pain. The pain persisted all that night and she was admitted to hospital next day (April 10, 1946) for investigation.

The patient was a well-nourished girl of 17 years, distressed and restless but alert and co-operative. Her temperature was $98.4^{\circ} \mathrm{F}$. $\left(36.9^{\circ} \mathrm{C}\right.$ ) , pulse 100 , and respirations 20 . Pallor was pronounced; the tongue was moist and there was no evidence of dehydration. The abdominal wall was held tightly, but moved with respiration, and no rigidity or tenderness could be detected; there was no visible peristalsis. Rectal examination was negative. The cardiovascular system was normal; the blood pressure was $130 / 60$. The lungs were clear and the central nervous system was normal. Radiographs of the abdomen showed no abnormality. Examination of the blood revealed a moderately severe microcytic anaemia. There was no leucocytosis. A fractional test meal was normal and a glucosetolerance test showed a normal resting blood sugar and curve. No sugar was present in the urine.

The first specimen of the urine was found to be dark red in colour, with a specific gravity of 1022 and a trace of albumin. Initially it was thought that the colour was due to an admixture of blood, as the patient was still menstruating, but a subsequent catheter specimen was also dark red, gave negative tests for blood, and showed no red cells in the spun deposit. Further specimens of urine were then examined in the Biochemistry Department of Queen's University, Belfast, and a porphyrin was isolated; details are given below. During the rest of her stay in hospital the patient continued to pass dark-red or reddish-brown urine, or, on rare occasions, pale urine which darkened on standing.

On questioning, the patient stated that she had first noticed the passage of reddish-brown urine some 21 months before admission to hospital. The abnormal colour was not present constantly, nor was there any relation between the passage of abnormally coloured urine and the attacks of pain.

\section{Progress}

After the first 24 hours in hospital the patient's condition improved considerably; the abdominal pain subsided, and by the fifth day she felt fit, and was eating and sleeping well. She was, however, still passing dark red urine. On the eighth day she complained of some weakness in her arms. Examination revealed some slight loss of power in the muscles of her shoulder girdles and upper arms-equal on both sides; reflexes were normal.

By the next day weakness in the arms was more pronounced and she had some loss of power in her legs. Neurological examination on the tenth day showed flaccid weakness of both arms and legs, especially in the proximal portion of the limbs. The reflexes were diminished or absent and the plantar responses were flexor. All forms of sensation were normal and there were no subjective sensory complaints. The cranial nerves were normal. During the next few days the weakness in the arms and legs gradually became more severe, but complete paralysis did not occur.

By the fourteenth day there was some weakness of the abdominal muscles, and the patient was unable to raise her head from the pillow; voluntary cough was also weak. There were no bulbar symptoms, voice and swallowing being normal. Micturition was normal, and mentally she was alert and orientated. For the next three days the patient's condition remained stationary, but on the eighteenth day her parents, who were greatly concerned by her condition, insisted on taking her home. At that time it was felt that her chance of survival was remote.

Recently it has been possible to interview and examine the patient again and to obtain details of the course of her illness following her discharge from hospital. A few days after her return home the motor weakness in her legs became less severe and she was able to sit up in bed and lift her hands above her head. During the next week or so she continued to improve, but then relapsed and experienced a severe burning pain in her feet ; this pain could be relieved to some extent by massage. So far as the patient was aware there was no impairment of sensation. With the onset of this pain the motor weakness returned rapidly to involve all four limbs once more. She remained in this helpless state, unable to move arms or legs, for some weeks, and her illness was further complicated at this time by an attack of jaundice of moderate severity. As the jaundice receded so her motor weakness gradually improved, and two months after leaving hospital the patient was able to sit up in bed unaided and move her arms and legs, although full power was by no means completely restored. Over the next three to four months her strength returned to normal, and by January, 1947, she was able to walk unaided out of doors. There were no further attacks of abdominal pain, and amenorrhoea persisted for seven months after the onset of the acute illness.

When examined in October, 1948, and again in May, 1949, the patient had no symptoms apart from periods of constipation which lasted from two to three days. Neurological examination was negative, and she looked and felt well. The urine was reddish orange to reddish brown in colour, and had been like that since she left hospital more than two years before. Menstruation was occurring every 21 days, but was no longer accompanied by attacks of abdominal pain. At the present time the patient remains well, though the urine is still abnormal in colour and contains uroporphyrin.

\section{Family History}

In view of the hereditary nature of acute porphyria, careful inquiries were made regarding possible evidence of the disease in other members of the family. 
The paternal grandparents of the patient were dead: the man had died of a stroke when 73 and the woman of heart disease when "elderly." The maternal grandparents were also dead : the man, of pneumonia, at 59, and the woman, of "old age," at 82. The patient's mother had a brother (aged 47) and a sister (49), both of whose urines were tested and found normal, as were those of a brother (46) and sister (48) of her father, whose other brother (54) and sister (c. 60) were in the United States and were said to be normal and healthy. The patient's father (51) and mother (52) showed no signs of porphobilinogen or porphyrin in their urine. Their only other child, a girl, had died at the age of 7 years after an attack of rheumatic carditis.

\section{Laboratory Investigations}

Methods.-Porphyrin spectra were measured with a Hartridge reversion spectroscope (Beck) calibrated against a mercury arc. Melting-point determinations were made with a microscope hot-stage and polarizing attachment, making it possible to use quantities of material of the order of a microgram. The apparatus was calibrated against a range of compounds of known melting-point as determined with a standard thermometer. All melting-points given in this paper are corrected.

\section{Findings}

During the acute attack in 1946 the freshly voided urine had a pink tinge. It exhibited the absorption bands of alkaline porphyrin on spectroscopic examination of a thick layer, and gave a strong pink fluorescence in ultra-violet light. It darkened on heating or on being allowed to stand. The Ehrlich reaction for porphobilinogen (Watson and Schwartz, 1941) was positive, the red pigment showing two absorption bands (at 561 and $500 \mathrm{~m} \mu$ ). This pigment was insoluble in chloroform. The Schlesinger test was negative. Ether extraction of the urine acidified with acetic acid gave very little coproporphyrin. A preparation of uroporphyrin made from 2 litres of urine by the barium adsorption method of Chandler, Harrison, and Rimington (1939) gave $9 \mathrm{mg}$. of crystalline uroporphyrin methyl ester melting at $263^{\circ} \mathrm{C}$.

Three years after the acute attack described above the appearance and reactions of the urine remained the same, except for the absence of porphyrin absorption bands (viewed in a layer of $8 \mathrm{~cm}$.) and the absence of pink fluorescence in ultra-violet light. Ether extraction of a sample $(100 \mathrm{ml}$.) of urine acidified with acetic acid gave only traces of coproporphyrin as judged by the fluorescence of an $\mathrm{HCl}$ extract of the ether.

Uroporphyrin was isolated from the urine by the following method. 2.5 litres of fresh unheated urine were brought to pH 3.7 with glacial acetic acid and stirred with $50 \mathrm{~g}$. of talc (B.D.H., "acid-washed"). The talc was filtered off, washed with a little dilute acetate buffer $p H$ 3.7, and the porphyrin together with a considerable amount of impurity eluted with two $40-\mathrm{ml}$. portions of $\mathrm{N} / 1$ ammonia. The combined eluates were brought to $p \mathrm{H} .3 .7$ with concentrated $\mathrm{HCl}$ and allowed to stand for an hour. The precipitate was filtered off, the filtrate stirred with $5 \mathrm{~g}$. of talc, and the porphyrin eluted with $25 \mathrm{ml}$. of ammonia. On bringing the eluate to $p \mathrm{H} 3.7$ a further precipitate of porphyrin came down and was combined with the first. The combined precipitates were suspended in $5 \mathrm{ml}$. of methyl alcohol saturated with $\mathrm{HCl}$ gas and allowed to stand overnight. The insoluble material was centrifuged off; the supernatant was mixed with three volumes of chloroform and then with excess ice-cold water. The $\mathrm{CHCl}_{3}$ layer was washed repeatedly with water, once with dilute ammonia, and finally twice with water. It was then dried over anhydrous $\mathrm{Na}_{2} \mathrm{SO}_{4}$, filtered, and evaporated to small bulk, and the porphyrin crystallized from a hot methyl-alcohol-chloroform mixture $(3: 1)$. The crystals were dissolved in a small volume of hot benzene and chromatographed on chaln. On development with benzene three porphyrin-like zones could be seen as judged by colour and by red fluorescence in ultra-violet light. The main wide band containing most of the porphyrin was separated from the rest of the column, the porphyrin eluted with $\mathrm{CHCl}_{3}$ and crystallized from hot $\mathrm{CHOH}-\mathrm{CHCl}_{3}$ mixture. The yield was $0.63 \mathrm{mg}$. of matted hair-like crystals, m.p. $271^{\circ} \mathrm{C}$. A dilute $\mathrm{CHCl}_{3}$ solution showed absorption bands at $626.7,571.8$ (maximum), 536.8, and $503.0 \mathrm{~m} \mu$. This corre- sponds closely to the absorption spectrum of a uroporphyrin octamethyl ester (Grinstein, Schwartz, and Watson, 1945). This porphyrin ester was rechromatographed from a petrol-ether/ benzene mixture $(1: 3)$ and developed with benzene. The main porphyrin ester from this chromatogram after recrystallization melted at $278^{\circ} \mathrm{C}$. This value is close to the melting-point obtained by Grinstein et al. for uroporphyrin octamethyl ester Type I, isolated from natural sources.

In order to obtain definite evidence that the porphyrin was of Type $I$, this material was decarboxylated to the corresponding coproporphyrin by heating in a sealed tube with $1 \%(\mathrm{w} / \mathrm{v})$ $\mathrm{HCl}$ at $185^{\circ} \mathrm{C}$. The product was re-esterified, chromatographed on chalk from $1: 1$ petrol-ether/benzene mixture, and developed with $1: 20$ choloroform-benzene mixture. The main porphyrin ester from this chromatogram showed absorption bands at 622.1, 596.2, 566.9 (maximum), 533.0, $498.9 \mathrm{~m} \mu$, corresponding closely to coproporphyrin methyl ester (Fischer and Orth, 1937). On crystallization the porphyrin ester was obtained as needles, melting point $224-239^{\circ} \mathrm{C}$., the latter temperature being the point at which double refraction was completely lost. There was not enough material for further purification. While there is some doubt about the melting-point of the methyl ester of coproporphyrin III (Jope and O'Brien, 1945), it appears to be about $150^{\circ} \mathrm{C}$., and is certainly much lower than that obtained for our product, which must have been mainly coproporphyrin I ester. This, taken in conjunction with the melting-point obtained for the uroporphyrin itself, makes it clear that the main uroporphyrin in the urine was the Type $I$ isomer.

The yield of preformed uroporphyrin $(0.63 \mathrm{mg}$. from 2.5 litres of urine) obtained during this remission stage of the disease is small, though it was found that it could be increased to several times the amount if the urine were heated at $p \mathrm{H} 3.7$ before starting the isolation.* During the acute attack the amount of uroporphyrin in the urine was much greater.

The specimens of urine from the patient's relatives were shown to be free from uroporphyrin and porphobilinogen by the following tests: negative Ehrlich test (Watson and Schwartz, 1941); failure to darken appreciably on heating or standing after acidification with acetic acid; absence of absorption bands; and absence of abnormal fluorescence in ultra-violet light.

\section{Discussion}

The clinical features of this case require little comment, for the patient presented many of the classical manifestations of acute idiopathic porphyria, including abdominal pain, constipation, vomiting, involvement of the central nervous system, and presence of uroporphyrin in the urine coupled with absence of skin symptoms and of photosensitivity. Of interest was the five-year history of recurrent abdominal colic associated with menstruation. It was felt that this pain was probably a manifestation of porphyria and not of spasmodic dysmenorrhoea, as the site and radiation were not typical of the latter condition; for in dysmenorrhoea the pain is usually felt in the lower abdomen, and radiation, when it occurs, is mainly to the sacrum and occasionally into the thighs (Holland, 1937). Moreover, the patient's pain, which occurred at the time of the menstrual periods, was identical with the pain experienced during the acute illness, differing only in extent and severity. While menstruation may usher in an acute attack of porphyria (Waldenström, 1937 ; Berg, 1945), we have not come across a case in the literature in which the acute attack was preceded by mild recurrent monthly attacks over so many years. The relation between menstruation and the underlying metabolic disorder is obscure.

Hypertension is said to occur often in acute porphyria (Waldenström, 1937; Denny-Brown and Sciarra, 1945).

*In recent work we have found that the extra porphyrin formed on heating the urine may be different in nature from the preformed uroporphyrin. (Gibson, Q. H., and Harrison, D. C. (1950). Biochem. J. In the press.) 
With the onset of the abdominal symptoms the blood pressure is at first within normal limits, but it may rise gradually thereafter to reach levels that are definitely hypertensive. In our case there was no hypertension : the diastolic pressure varied between 60 and $70 \mathrm{~mm} . \mathrm{Hg}$, while the highest systolic pressure recorded was $135 \mathrm{~mm}$. Hg. Leucocytosis, another frequent manifestation of acute attacks (Mason, Courville, and Ziskind, 1933), was also absent.

An interesting feature regarding this patient is her remarkable recovery following severe involvement of the nervous system. The extensive reviews of Mason et al. (1933) and of Waldenström (1937) indicate that the mortality rate in acute attacks is above $50 \%$, and with neurological involvement the figure is much higher. Discombe and D'Silva (1945), however, described a case in which a man suffered an acute attack of porphyria with abdominal and neurological symptoms, which was followed by six relapses in three years. In spite of this the man recovered, and there was almost complete restoration of function in the paralysed muscles, though he continued to excrete uroporphyrin.

Mason et al. (1933) say that motor paralysis may develop rapidly or rather slowly, and they consider that recovery is not unusual in the more slowly progressive case. They do not, however, state precisely what they mean by these terms, and we therefore do not know into which group they would have placed our patient, the extension of whose neurological involvement occupied a total of seven days. In a case reported by Denny-Brown and Sciarra (1945), 16 days elapsed between the onset of motor weakness and its maximum severity. This patient slowly recovered from the attack, but died two years later, after a second attack with bulbar involvement.

The family history in the present case deserves comment. The current view is that acute porphyria is transmitted by a dominant gene which shows a small degree of penetrance. The absence of any manifestation of the disease in the members of the generation previous to that of the patient is not uncommon, but it was surprising to find on testing the urines of six members of this generation, including the mother and father, that there was no instance of the latent form of the disease, with urinary chromogens or porphyrins indicative of deranged pyrrole pigment metabolism. In cases in which the urine of both parents could be tested, Waldenström found only two instances in which neither parent showed any evidence of this abnormality.

Waldenström (1937) has shown the strikingly high incidence of acute porphyria in Scandinavia, suggesting a genetic background relatively favourable to the disease compared with that in England, for example, where the number of reported cases is very small. On the basis of past migratory tendencies from Scandinavia, Discombe (1948) suggested that cases of acute porphyria might be less rare in Scotland and Northern Ireland than in England. So far as we are aware, the present case is the first to be reported in Northern Ireland. On questioning, the parents stated that they knew. of no Scandinavian link in their ancestry.

Until recently it was commonly believed that patients with acute porphyria excrete Type III uroporphyrin, in contrast to those with congenital porphyria, who excrete the Type I porphyrin. The work of Turner (1938) and of Watson, Schwartz, and Hawkinson (1945) threw doubt on this belief, and in the last few years several cases have been reported in which Type I porphyrin was excreted by patients with acute porphyria. Our patient falls into this category, and it is clear that the porphyrin type is not a diagnostic criterion for differentiating acute and congenital porphyria. A further implication is that in both diseases the porphyrin is likely to have arisen through an abnormality in the reactions involved in the building up of the pyrrole pigment rather than in those involved in pigment breakdown. Haemoglobin is made up of Type III pigment, and the degradation of this to a Type I porphyrin seems very unlikely.

As pointed out by Waldenström and others, the term "acute porphyria" is unfortunate, for it focuses attention on the acute episode of the disease and obscures the underlying chronic disorder of metabolism which exists between the severe attacks. The use of this term is understandable, of course, for the disease is rare, and physicians usually see the patient only in the acute attack, an attack which is often fatal.

In patients who recover, the warding off of further acute attacks is of paramount importance, since there is no known effective treatment for the acute episode. So far, all that can be done in this direction is to warn the patient of the danger of taking drugs which are known to produce porphyrinuria. Among those listed by Dobriner and Rhoads (1940) are barbiturates, sulphonamides, arsenicals, sulphonal, and alcohol. Barbiturates in particular have been mentioned by a number of workers as being potentially dangerous to these patients.

\section{Summary}

A case of acute porphyria is described in which a remission of two and a half years' duration has followed an acute attack with abdominal symptoms and severe paralysis.

The urine still contains porphyrin, which has been identified as uroporphyrin Type I. The urine of both parents and of all other relatives tested is free from porphyrin and its precursors.

We wish to thank Dr. S. B. Boyd Campbell for permission to publish details of this case, and Dr. C. L. Wilson for lending us the micromelting-point apparatus.

\section{REFERENCES}

Berg, M. (1945). Arch. intern. Med., 76, 335.

Chandler, F. G., Harrison, G. A., and Rimington, C. (1939). British Medical Journal, 2, 1173.

Davies, D. (1949). Ibid., 1, 846

Denny-Brown, D., and Sciarra, D. (1945). Brain, 68, 1

Discombe, G. (1948). British Medical Journal, 2, 659.

and D'Silva, J. L. (1945). Ibid., 2, 491.

Dobriner, K., and Rhoads, C. P. (1940). Physiol. Rev., 20, 416.

Fischer, H., and Orth, H. (1937). Die Chemie des Pyrrols, 2, 484. Leipzig.

Grinstein, M., Schwartz, S., and Watson, C. J. (1945). J. biol. Chem., $157,323$.

Hare, L., and Wilmore, R. (1948). Amer. J. Med., 5, 53.

Holland, E. (1937). The British Encyclopaedia of Medical Practice. 4, 356. London.

Jope, E. M., and O'Brien, J. R. P. (1945). Biochem. J., 39. 239.

Mason, V. R., Courville, C., and Ziskind, E. (1933). Medicine, 12 355.

Petrie, E. (1948). British Medical Journal, 1, 926.

Turner, W. J. (1938). Arch. intern. Med., 61, 762.

Waldenström, J. (1937). Acia med. scand., Suppl. 82.

Watson, C. J., and Schwartz, S. (1941). Proc. Soc. exp. Biol., N.Y. 47, 393 .

and Hawkinson, V. (1945). J. biol. Chem., 157, 345.

The World Health Organization gradually expanded its activities during 1949, and in addition to its headquarters at Geneva has three regional offices in operation at New Delhi, for Southeast Asia; at Alexandria, for the Eastern Mediterranean; and at Washington, for the American continent. Other regional offices will be opened to cover Europe, Africa, and the Western Pacific area. It also maintains field offices in China and Ethiopia, and an epidemiological intelligence station at Singapore. The total staff serving in the field and in offices is just under 400 , representing 41 nationalities. At the end of 1949, 67 nations were members of WHO. 